Egyptian

Orthodontic Journal

\title{
IN VIVO STUDY OF THE EFFECTIVENESS OF OZONIZED OLIVE OIL GEL ON INHIBITING ENAMEL DEMINERALIZATION DURING ORTHODONTIC TREATMENT
}

\author{
Safaa Ali Ghobashy ${ }^{1}$, Heba Mohamed El-Tokhey ${ }^{2}$
}

ABSTRACT:

The present study assessed the effect of ozonized olive oil gel during orthodontic treatment to infibit demineralization around orthodontic brackets.

Material and Methods: Fourteen patient, aged 15-18 years, scheduled to have premolars extraction as a part of orthodontic treatment participated in the present study. The patients were randomly divided into 3 groups; control group (16 upper and lower premolars) and two experimental groups (20 upper and lower premolars for each). In the Control group no treatment was applied on the premolars. In experimental groups, after etching and bonding, $\mathcal{T}$-loops were formed with 0.014 inch stainless steel wire and engaged on the experimental teeth. In experimental group II, ozonized olive oil gel was applied sparingly to the tooth surface with concentration of 20:25 $\mathrm{\mu gm} / \mathrm{ml}$. Participants were instructed to apply the ozonized olive oil gel to the buccal surface of the premolars three times daily for 8 weeks after regular oral hygiene procedures. After 8 weeks, the brackets were deboned and the premolars extracted carefully. The premolars of each group were divided into 2 equal numbers; 28 premolars prepared for elemental analyses (calcium and phosphorus) followed by scanning electron microscope investigation, and 28 premolars examined with polarized light. ANOVA test was applied followed by post hoc LSD test to compare between each 2 groups.

\footnotetext{
1 - Associate Prof. of Orthodontics, Faculty of Dentistry, Tanta University.

2 - Associate Prof. of Oral biology, Faculty of Dentistry, Tanta University.
} 
Egyptian

Orthodontic Journal

Results: Ca/P ratio of enamel in control group was 3.09. In experimental group $I$, the Ca/P ratio reduced to 1.75 , while in group II, the ratio was 2.33, with statistically significant difference between all groups. Polarized light examination of experimental group I revealed increased depths of demineralized areas, and extending deeper in the enamel which was indicated by positive form birefringence. Experimental group II showed the enamel surface with improvement of demineralized lesions in the form of negative form birefringence resembling normal enamel in the control group. Scanning electron microscopic examination of experimental group I showed comparatively increased depths of demineralized areas with deep wavy perikymata. Enamel surface of experimental group II showed almost normal appearance of perikymata, with new hydroxyapatite crystal deposition.

Conclusion: The use of ozonized olive oil gel in addition to the standard oral hygiene regimen was found to be beneficial for orthodontic patients to prevent enamel decalcification during treatment.

\section{INTRODUCTION}

Despite the advances in orthodontic materials and techniques in recent years, the development of decay around brackets during orthodontic treatment continues to be a problem ${ }^{1}$. The presence of orthodontic attachments makes patient's dental hygiene more difficult and the accumulation of plaque easier ${ }^{2,3}$. This environment changes the biological balance of the mouth and increases the patient's risk of caries ${ }^{4-7}$. In addition it may restrict the ability of the tongue to remove food particles from the mouth ${ }^{8}$.

After the use of fixed appliances, decalcification marks are more pronounced at the gingival third of the teeth, where higher plaque accumulation usually occur ${ }^{9}$.Clinically, they appear as white opaque spot chalky lesions around the brackets. White spot lesions are softer than the surrounding enamel ${ }^{10}$. They are seen as early as 4 weeks after band/ bracket placement ${ }^{4,5}$. The obvious degree of iatrogenic enamel damage during orthodontic treatment suggests the need for preventive programs. 
Egyptian

Orthodontic Journal

The two methods that have been proposed to date to prevent white spot formation include professional hygiene instructions and enamel surface modification by means of fluoride agents, chlorhexidine, sealants, or Nd: YAG laser and others ${ }^{11-16}$.

In the field of conservative dentistry, ozone has gained popularity as a means of preventing dental caries ${ }^{16,17}$. Ozone is a natural oxidant consisting of three atoms that is also known as triatomic oxygen. Ozone treatment is reported to inactivate microorganisms that cause tooth decay, with no negative interactions with the physical properties of enamel and adhesive restorations ${ }^{18}$. The effects of gaseous ozone and aqueous ozone have been investigated in several studies ${ }^{19-25}$.

Ozone gas dissolved in plant oils, such as olive oil, is being discussed in dentistry for its excellent antimicrobial property, without the development of drug resistance and facilitation of wound healing ${ }^{26-29}$. In orthodontics, clinicians tend to seek out an effective antimicrobial agent to apply prior to bracket bonding in order to prevent dental caries during fixed appliance treatment ${ }^{30-34}$. Despite the current lack of substantiated evidence for the benefits of its application, ozone may prove a viable alternative to conventional prophylactic treatments in the near future ${ }^{35}$. In light of various findings in conservative dentistry ${ }^{36}$, it seems appropriate to speculate that application of ozone gas for 20 seconds around orthodontic brackets during interval visit will prevent or reduce the potential of demineralization and development of white spot lesions without affecting the shear bond strength of the bonded brackets ${ }^{37,38}$.

Although ozone appears to be an integral part of noninvasive therapy of dental caries, specifically as a disinfectant prior to placing a direct restoration $^{36,39-41}$, knowledge of its in-vivo effect on enamel surface around the orthodontic brackets still deficient. The present study aimed to determine quantitatively and qualitatively:

- The amount and extent of demineralization occurring around orthodontic appliance after 2 months in vivo.

- The ability of ozone olive oil gel to inhibit such orthodontically related demineralization. 


\section{MATERIALS AND METHODS}

Fourteen patients, aged 15- 18 years, scheduled to have premolars extraction as a part of orthodontic treatment participated in the present study. The criteria for inclusion in this study were: intact buccal enamel, absence of any clinical evidence of demineralization lesions, lack of visible structural defects on enamel and no restorations on the surface. The patients were duly informed about the study and signed informed consent forms. The buccal surfaces of the maxillary premolars were polished with fluoride-free pumice and rubber cup for 10 seconds, sprayed with water and dried with compressed oil-free stream. Precise oral hygiene instructions were given to all patients.

The patients were randomly divided into 3 groups; control group and two experimental groups. A total of 56 premolars were involved including 16 in the control, and 40 in the experimental groups, 20 for each (Fig 1).

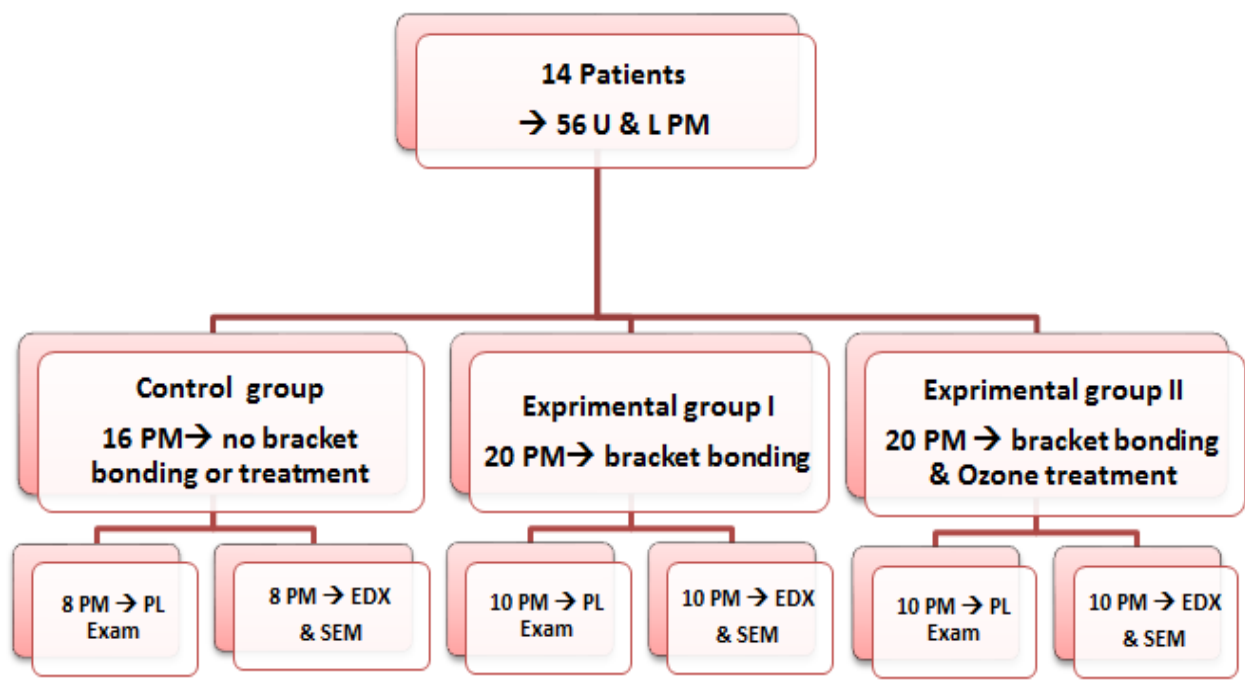

Fig (1): Illustration of study design. U\&L $P M=$ upper and lower premolars, $\mathrm{PL}$ Exam= polarized light examination, $\mathrm{EDX}=$ energy dispersive $\mathrm{x}$-ray analysis, SEM=scanning electron microscope. 


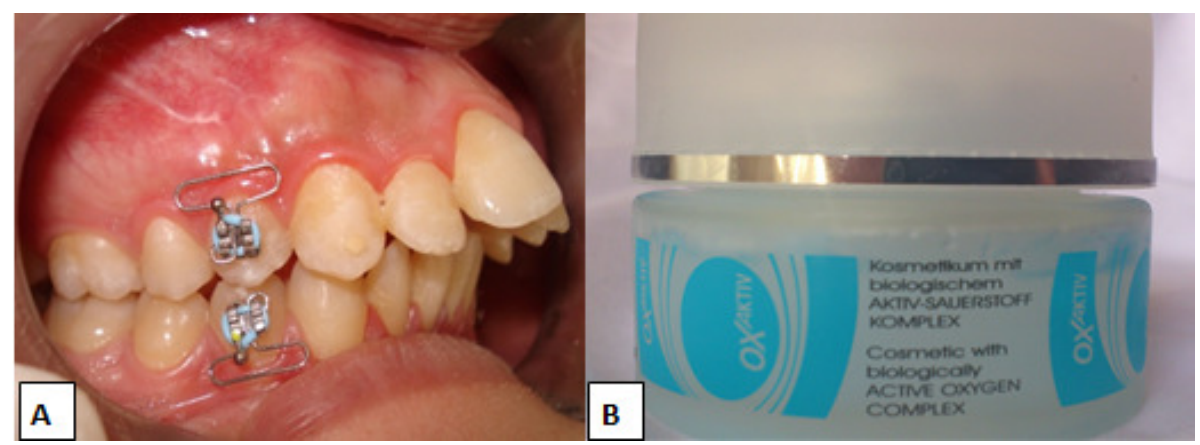

Fig (2) A: Intraoral photograph showing the bonded brackets and T-loops were formed with 0.014 inch stainless steel wire and tied with elastomeric rings. B: The jar of ozonized olive oil gel

\section{Control group:}

No treatment was applied on the premolars. The patients in this group instructed to brush daily with the supplied dentifrice.

\section{Experimental group I: Bracket bonding without enamel treatment}

A $37 \%$ phosphoric acid gel was applied to the enamel surface area corresponding to the bracket base for 30 seconds. The acid gel was washed with water jet, tooth surface dried and the bracket bonded to the enamel surfaces following manufacturer's instructions with a fluoride free self-curing composite (Rely A Bond; Reliance Orthodontic Products, Itasca, II, USA). The brackets (American orthodontics/ mini master series) were positioned on the facial surface at the height of contour mesiodistally, in the middle third occlusogingivally, and parallel to the long axis of the tooth, and pressed on the enamel surface until fully seated. Excessive adhesive around the bracket was removed with a clinical probe. T-loops were formed with 0.014 inch stainless steel wire and engaged on the experimental teeth with elastomeric rings after 1 hour of bonding (Fig 2, A).

\section{Experimental group II: Bracket bonding and treatment of enamel with ozonized olive oil}

After etching, bonding, and ligation of T- loops as done in group I, the premolars were kept dried by careful tooth isolation and the enamel 
Egyptian

Orthodontic Journal

received a single topical application of a small dab of the ozonized olive oil gel with concentration of 20:25 $\mu \mathrm{gm} / \mathrm{ml}$ (Pharmoxid Arznei Gmb H \& Co.KG, Ifferzheim, Germany, Fig 2,B) sparingly to the tooth surface with the aid of a brush applicator. Participants were instructed to apply the gel to the buccal surfaces of the premolars three times daily for 8 weeks after regular oral hygiene procedures. The subjects were monitored weekly for application reinforcement, and supplied with a list of specific instruction outlining the sequence of brushing and application of ozonized gel. To ensure compliance, the subjects noted the time of brushing and checklist, which the parent or guardian signed daily. After 8 weeks the brackets were deboned and the premolars extracted carefully, scrapped and cleaned of remnants of periodontal ligaments, and fixed in a solution containing $2.5 \%$ formaldehyde freshly prepared from Para-formaldehyde. The roots were separated from the crowns with diamond discs under water spray just at the cemento- enamel junction, then each crown was cut on a mesiodistal line from occlusal to cervical and the buccal surfaces were used for the study.

\section{Scanning electron microscope examination:}

For scanning electron microscope study, the premolar crowns were washed with distilled water, dehydrated in grades of ethanol baths and dried in air. The specimens were mounted on aluminum stubs. Firstly, they were subjected to x-ray microanalysis, then they were coated with gold in a high vacuum evaporator to thickness of $10 \mathrm{~nm}$. The cervical, middle and occlusal thirds of the buccal surfaces were examined with a scanning electron microscope (JEOL JSM 5410, Tokyo, Japan), at $25 \mathrm{KV}$ at the Faculty of Science, Alexandria University.

\section{Energy dispersive X-ray analysis:}

Energy dispersive X-ray analysis (elemental microanalysis) cervical to the bracket was performed. A total of 10 analysis were done in each experimental group, and 8 in control group. Thus, elementary chemical analysis for calcium and phosphorus were obtained (mineral components) and the $\mathrm{Ca} / \mathrm{P}$ ratio for each analysis was calculated for subsequent statistical analysis.

Volume 41 - June 2012 
Egyptian

Orthodontic Journal

\section{Polarized light examination:}

The premolar crowns of each group were sectioned buccolingually adjacent to midline (Fig 3) using water cooled diamond disc and further by hand grinding on polishing boards until a thickness of about 100:120 microns was obtained. The samples were then washed with deionized water, and mounted longitudinally on glass cover slides.

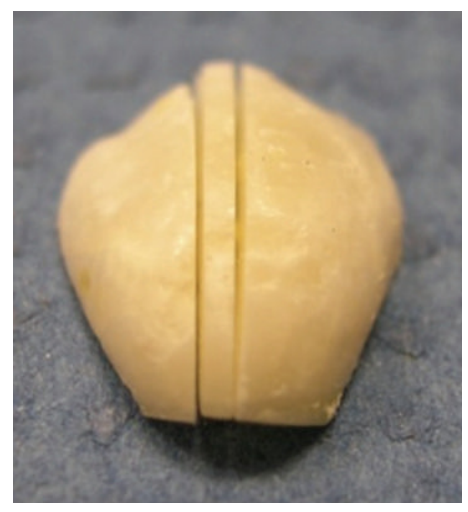

Fig (3): The position of cutting through the crown for polarized light examination.

The teeth in the three groups were then examined under a polarized light microscope (Olympus dual stage, CX 31 Japan) in Geology Department in Faculty of Science Alexandria University and photographed with magnifications X40 (Fig 4:8 A) and X 100 (Fig 4:8 B).

\section{Statistical analysis:}

Analytic data were collected and analyzed using SPSS version 18 under windows 7. Statistical analysis was done using one way ANOVA test to compare the $\mathrm{Ca}, \mathrm{P}$, and $\mathrm{Ca} / \mathrm{P}$ ratios of enamel surface in each group, followed by post hoc LSD test to compare between each 2 groups. The value of significance was set at $\mathrm{p}<0.001$.

\section{RESULTS}

\section{Energy dispersive X-ray analysis:}

It was seen that for all the study groups the comparison revealed very highly significant differences among groups (Table 1 ). $\mathrm{Ca} / \mathrm{P}$ ratio of 
enamel in control group was 3.09. In experimental group $\mathrm{I}$, the $\mathrm{Ca} / \mathrm{P}$ ratio reduced to 1.75 , while in group II, the ratio was 2.33. Post hoc test showed statistical significant difference between all groups.

Table (1): Elemental analysis

\begin{tabular}{|l|c|c|c|c|c|c|}
\hline Minerals & Mean & \pm SD & Min. & Max. & ANOVA- F & P value \\
\hline PKa & & & & & & \\
control & 21.09 & 1.26 & 21.5 & 23.3 & 235.12 & $\mathrm{P}<0.001^{* *}$ \\
group I & 33.35 & 1.56 & 32.1 & 35.2 & & \\
group II & 28.01 & 2.92 & 23.9 & 30.00 & & \\
\hline $\begin{array}{l}\text { CaKa } \\
\text { control }\end{array}$ & 68.04 & 1.68 & 66.9 & 69.0 & & \\
group I & 58.68 & 1.78 & 56.5 & 61.3 & & \\
group II & 65.20 & 1.99 & 61.30 & 68.5 & & \\
\hline $\begin{array}{l}\text { Ca/P } \\
\text { ratio } \\
\text { control }\end{array}$ & 3.09 & 0.3 & 3.0 & 3.90 & & \\
group I & 1.75 & 0.5 & 1.5 & 1.90 & 256.74 & $\mathrm{P}<0.001^{* *}$ \\
group II & 2.33 & 0.19 & 2.05 & 2.86 & & \\
\hline
\end{tabular}

**Significant at $\mathrm{P}<0.001$.

\section{Histological findings of the polarized light microscope}

The histological results of the polarized light microscopic sections demonstrated variations in the depths and areas of the demineralized lesions among the three groups.

Control Group: The enamel surface of this group appeared to have the least depth of demineralized areas. This was represented by the negative form birefringence in the body of the lesion (translucent zone) (Fig4). Some lesions showed very faint positive form birefringence band at the inner border of the lesion (Fig 5). In all control samples the surface prismless enamel layer was intact.

Experimental Group I: The enamel of this group showed comparatively increased depths of demineralized areas, affecting the 
surface of some specimens, body of the lesion and extending deeper in the enamel which were indicated by positive form birefringence (Fig 6 and 7).

Experimental Group II: The enamel of this group showed comparatively improvement of demineralized lesions. This appeared in the form of negative form birefringence (Fig 8).

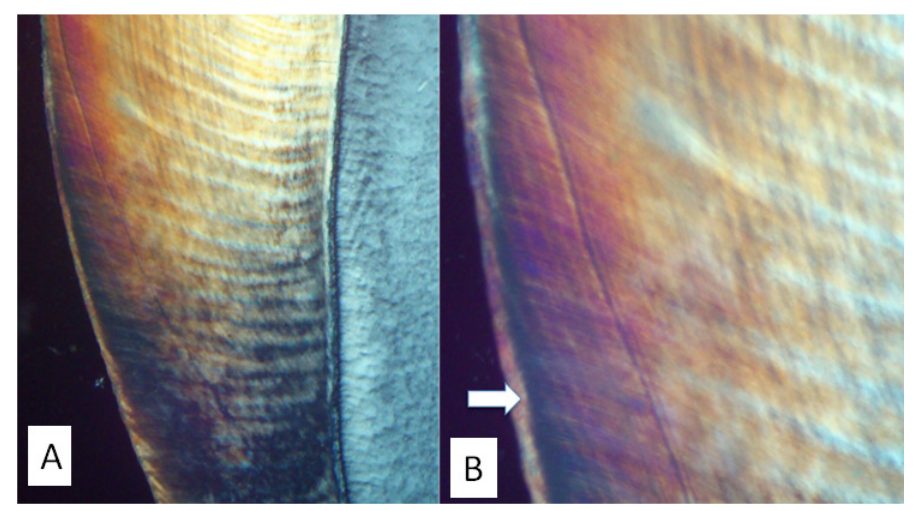

Fig (4): Polarized light micrographs of longitudinal ground sections of control group showing translucent zone with intact outer surface of enamel (arrow).

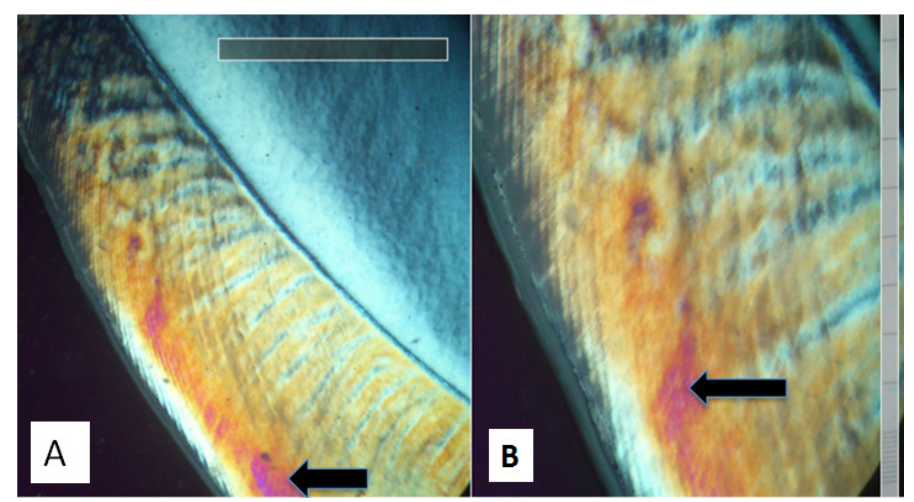

Fig (5): Polarized light micrographs of longitudinal ground sections of control group showing the translucent area and a very faint band (arrows) at the inner border of the lesion the scale on the figure equal to $1 \mathrm{~mm}$. 


\section{Egyptian}

Orthodontic Journal

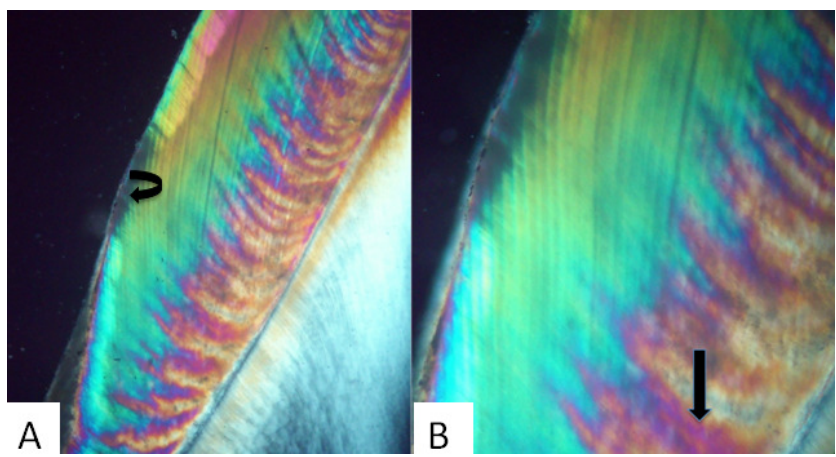

Fig (6): Polarized light micrographs of the longitudinal ground sections of the enamel of experimental group I showing laminated, broad, dark, positive birefringent zone. Note the outer enamel surface is partially demineralized (curved arrow).

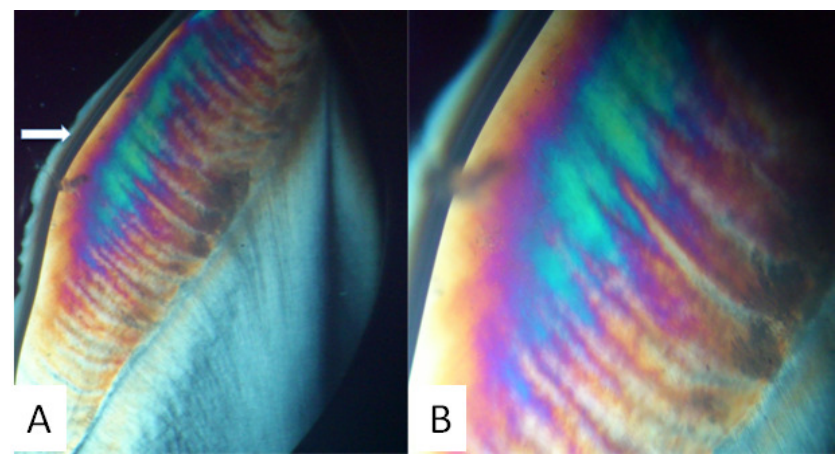

Fig (7): Polarized light micrographs of longitudinal ground sections of the enamel of experimental group I showing larger area of laminated, broad, dark, positive birefringent zone. The outer enamel surface (arrow) is still intact.

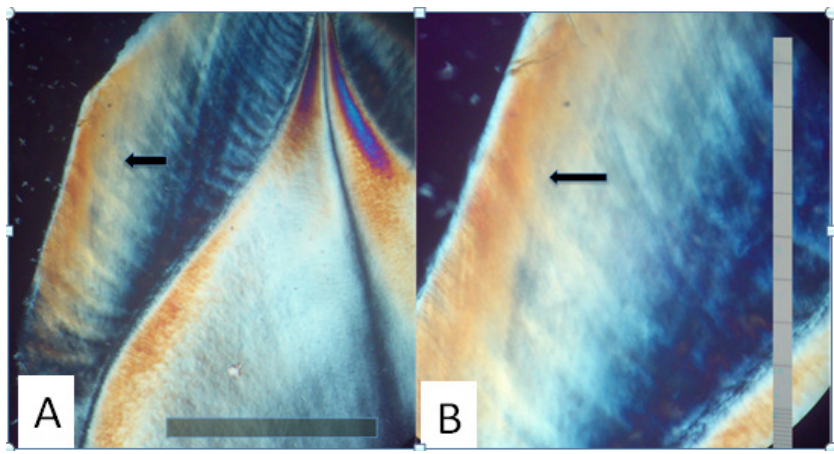

Fig (8): (A \& B) Polarized light micrographs of longitudinal ground sections of enamel of experimental group II showing translucent zone with negative form birefringence indicated by arrows. 
Egyptian

Orthodontic Journal

\section{Scanning electron microscope evaluation:}

Scanning electron microscope examination of the enamel surface in control group showed normal appearance of perikymata at cervical third while the middle and occlusal thirds showed smooth surface of enamel with some scratches (Fig 9). In contrast, the enamel surface of experimental group I showed deep wavy perikymata occupies most of the buccal surface with exposure of enamel rod ends in furrows between perikymata (Figs 10\& 11).

Experimental group II showed almost normal appearance of perikymata restricted to the cervical third while enamel of middle and occlusalthirds were almost smooth except minimal fissures (Fig 12). Occasionally, rough enamel surface and irregular depressions of variable size that did not expose the enamel rod ends with new hydroxyapatite crystal deposition were detected (Fig 13).

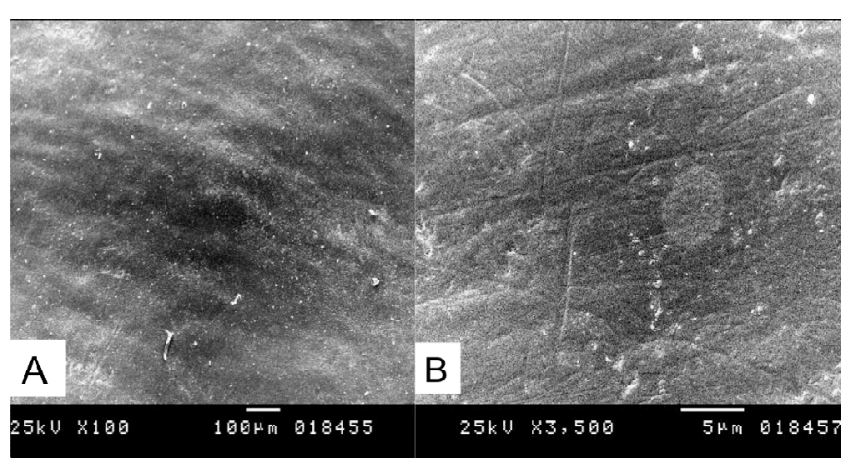

Fig (9): SEM of enamel surface of control group showing normal appearance of perikymata at cervical third (A). The middle and occlusal thirds showing smooth surface of enamel with some scratches (B).

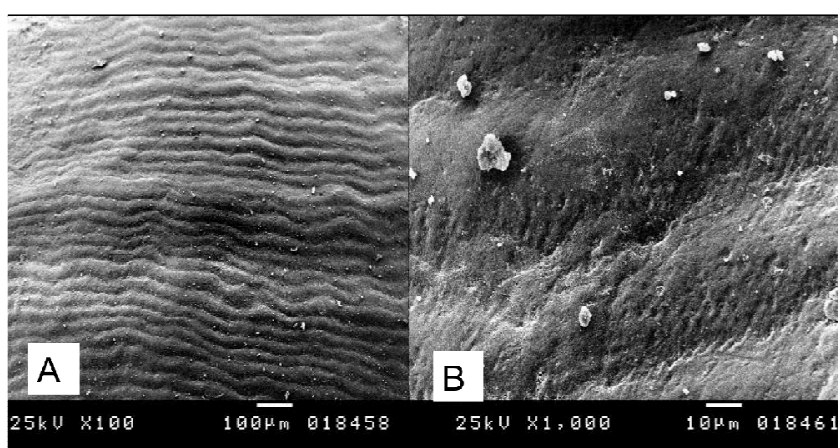

Fig (10): SEM of enamel surface of experimental group I showing deep wavy perikymata occupy most of the buccal surface (A). Higher magnification of the previous figure showing exposed enamel rod ends in the furrows between perikymata (B). 


\section{Egyptian}

Orthodontic Journal

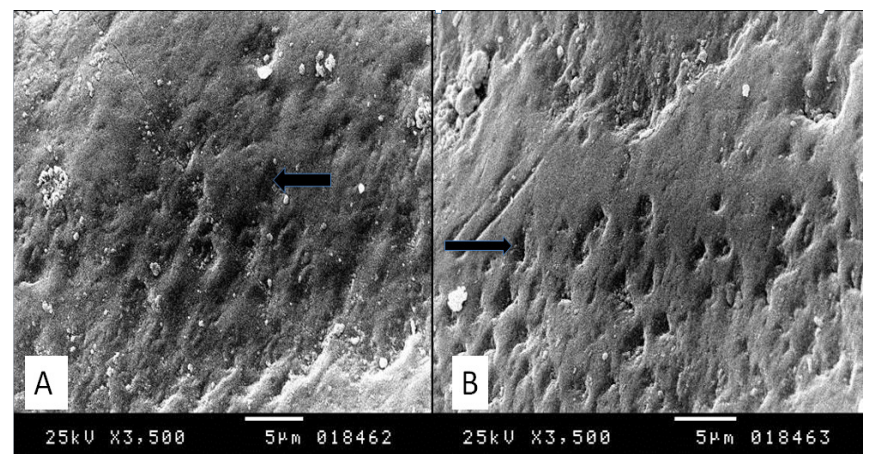

Fig(11): SEM of enamel surface of experimental group I, showing exposed enamel rod ends with characteristic key holes appearance (arrows in A and B).

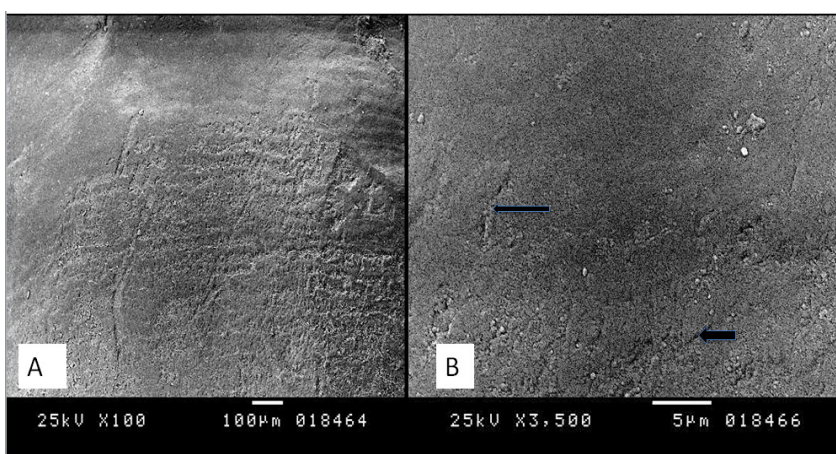

Fig (12): SEM of enamel surface of experimental group II (A) showing almost normal appearance of perikymata restricted to the cervical third the enamel of middle and occlusal thirds with almost smooth surface except minimal fissures (arrows, B).

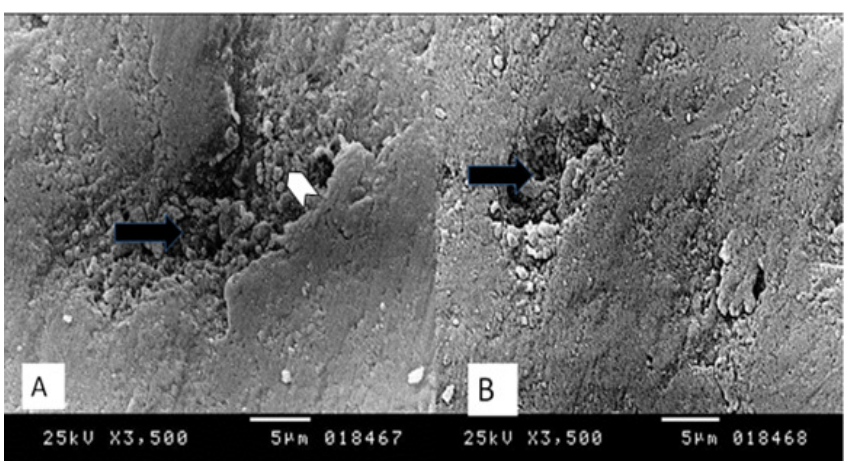

Fig (13): (A \& B) SEM of enamel surface of experimental group II showing rough enamel surface and an irregular depression (arrow) that did not expose the enamel rod ends. Note the deposition of new hydroxyapatite crystals (arrow head). 
Egyptian

Orthodontic Journal

\section{DISCUSSION}

The foremost goal of orthodontic treatment is to improve function and aesthetics. To achieve these goals, the orthodontist must do extensive preventive treatment to maintain tooth structure.

In spite of optimal oral hygiene measures, there is a chance of developing white spot lesions during orthodontic treatment with fixed appliances, which may present subsequent aesthetic problems that need to be considered. Assessment of ozone's effect on caries of permanent teeth showed that ozone reverse caries in the surface lesion by shifting the chemical balance promoting remineralization of tooth structure regardless of lesion type or location ${ }^{22}$.Ozone gas application around orthodontic brackets was described as a new protocol to reduce enamel demineralization ${ }^{42}$. For that, the present study was conducted to prove the capability of ozone treatment to reduce the development of white spot lesions during fixed orthodontic treatment.

Although the ozonized water is easy to use, the concentration became a half in about 30: 40 minute ${ }^{43}$. It was found that ozone could be kept for a long time by making a virgin olive oil dissolve ozone, under controlled cooling and pressure reaction, and obtained in gel form ${ }^{44}$. In the present study, ozonized olive oil gel was used, and for accurate prophylaxis, it was applied three times daily as the effect of ozone reduced gradually by time ${ }^{45}$. Energy dispersive X-rays analysis has been used for elemental analysis at the ultra-structural level. It is one of the latest micro-analytical techniques that are used in conjunction with scanning electron microscope as an efficient way to quantitatively assess the changes in mineral content ${ }^{46}$.

The results of the current study showed that ozonized olive oil gel have a substantial ability to preserve the $\mathrm{Ca}$ and $\mathrm{P}$ contents in enamel by its protective effect against decalcification of teeth although the $\mathrm{Ca} / \mathrm{P}$ ratios (2.33) did not reach the values of sound enamel (3.09). Since the $\mathrm{Ca}$ and $\mathrm{P}$ are the main components of hydroxyapatite crystals ${ }^{47}$, it might be said that ozonized olive oil gel could decrease the potential of decalcification during orthodontic treatment. 
Egyptian

Orthodontic Journal

In experimental group $\mathrm{I}, \mathrm{Ca} / \mathrm{P}$ ratio was decreased to the extent of 1.75 , which denoted reduction in the crystallinity and an increase in the extent of dissolution of the apatite with subsequent enamel destruction ${ }^{48}$. This result was matched with polarized light and scanning electron microscope observations. The results of polarized light examination of group II showed the enamel surface with comparatively improvement of demineralized lesions. This appeared in the form of negative form birefringence resemble the normal enamel in control group. Scanning electron microscope revealed that the surface texture demonstrated almost normal appearance of perikymata with almost smooth surface except minimal fissures. Enamel surface roughness and irregular depressions could be detected with no exposure of the enamel rod ends.

The efficiency of ozone treatment in reducing decalcification around orthodontic brackets was explained by the fact that ozone can significantly reduce the number of Streptococcus mutans in plaque, and effectively penetrate into the lesion and kill the great majority of micro-organism, resulting in a delayed recolonization compared with untreated enamel surface ${ }^{42}$. The re-application of ozone could slow the recolonization pattern and achieve long-term suppression. Ozone enables the shifting of microbial flora from acidogenic and acidouric microorganisms to normal oral commensals, which will allow remineralization to occur ${ }^{49}$. It has the ability to remove protein in carious lesion and to enable $\mathrm{Ca}$ and $\mathrm{P}$ ions to diffuse through the lesions leading to remineralization ${ }^{50}$. Accordingly, in the current study, new hydroxyappitite crystal depositions could be seen adjacent to the small area of demineralizationon of the surface treated with ozone application. Saliva could be considered as another factor which led to the remineralization as Amaechi and Higham ${ }^{51}$ speculated that, saliva with its mineral content, can possess a reparative effect on early erosion which is characterized by softened surface and slight subsurface demineralization in addition to a crater.

Dahnhardt et $\mathrm{al}^{22}$, Al-shamsi ${ }^{42}$ and ALjehani et $\mathrm{al}^{52}$ support the results of the present study. In contrast, Kronenberget $\mathrm{al}^{38}$ reported low effects of gaseous ozone on white spot lesions. They evaluated the preventive effect of ozone on the development of white spot lesions 
Egyptian

Orthodontic Journal

during multibracket appliance therapy. Their patients were selected with very poor oral hygiene, with an average observation period of 26 months. This conflict may be due to using the ozone as a remineralization tool, rather than an antibacterial agent ${ }^{53}$.Furthermore, white spot formation or enamel decalcification was evaluated visually and by quantitative light-induced fluorescence using a DIAGNO dent device, which does not seem to be a suitable device for the detection of initial lesions during fixed orthodontic treatment ${ }^{54-56 .}$

In experimental group I, the untreated enamel surface showed partial enamel demineralization, affecting the surface of some specimens extending deeper in the enamel which were indicated by positive form birefringence with polarized light. Scanning electron microscope demonstrated more surface changes that revealed exposed enamel rod ends with spreading of focal holes and more accentuation of the perikymata. The numerous so-called focal holes observed along the perikymata are not empty spaces but most likely are filled with organic material, which considered as the initial sites of acid penetration that diffuse easily into the defects and then into the spaces between the crystallites $^{57,58}$

Decalcification of untreated enamel with orthodontic treatment is to be expected and reported earlier, as tooth brushing and flossing become more challenging in the presence of the orthodontic appliances ${ }^{59,60}$. Several studies have revealed that Streptococcus mutants colonization in plaque was higher in teeth with fixed orthodontic appliances compared with control teeth without appliances ${ }^{61,62}$. Plaque acts as a physical barrier for the diffusion of acid away from the enamel surface and it can also prevent remineralization by calcium and phosphate ions from the saliva. Moreover it is a source of acid production in the presence of fermentable substrate attaching directly to enamel ${ }^{8}$. Also, during orthodontic treatment acid etching and composite resin adhesives increase enamel decalcification $^{63}$. Acid etching dematerializes the enamel surface, exposes the enamel rods and prisms, and removes the protective acquired pellicle ${ }^{63,64}$. The exposed enamel rods provide a way for the bacteria and cariogenic by-products. So it is essential for the orthodontist to be proactive in oral hygiene control during treatment and in monitoring all patients closely. 
Egyptian

Orthodontic Journal

\section{CONCLUSION}

- There was significantly less decalcification of teeth that were protected with ozonized olive oil gel than do teeth not protected.

- The uses of ozonized olive oil in addition to the regular oral hygiene regimen were found to be beneficial for orthodontic patients in preserving the enamel surface.

\section{RECOMMENDATIONS}

No study in the literature so far shows complete prevention of enamel decalcification ${ }^{65}$, so good oral hygiene and proper diets are still more effective than any adjunctive agent. It is important to continue the development of a preventive agent that can be effectively delivered in the orthodontic patient who lacks compliance with oral hygiene.

\section{ACKNOWLEDGMENT}

The authors express their gratitude to Dr. Ahmed Fathi, Head of Surgery and Ozone treatment Department in Marine Academy, Rass-Eltin, for his scientific support and providing the ozonized organic olive oil used in this study.

\section{REFERENCES}

1. Gorton J, Featherstone JD. In vivo inhibition of demineralization around orthodontic brackets. Am J Orthod Dentofacial Orthop 2003;123:10-14.

2. Saloum SS, Sondhi S. Preventing enamel decalcification after orthodontic treatment. J Am Dent Assoc 1987;115:257-261.

3. Ceen RF, Gwinnett AJ. Plaque pattern and crevicular fluid related to orthodontic bracket bonding. J Prev Dent 1980;6:229-233.

4. O'Reilly MM, Featherstone JD. Demineralization and remineralization around orthodontic appliances: an in vivo study. Am J Orthod Dentofacial Orthop. 1987; 92: 33-40.

5. Ogaard B, Rolla G, Arends J. Orthodontic appliances and enamel demineralization. Part 1. Lesion development. Am J Orthod Dentofacial Orthop 1988;94:68-73. 
6. Ogaard B, Rolla G, Arends J, ten Cate JM. Orthodontic appliances and enamel demineralization. Part 2. Prevention and treatment of lesions. Am J Orthod Dentofacial Orthop 1988;94:123-128.

7. Shannon IL prevention of decalcification in orthodontic patients JCO.1982; 15:694-705.

8. Chang $\mathrm{H} \mathrm{S}$, Walsh $\mathrm{L} \mathrm{J}$ and Freer $\mathrm{T} \mathrm{J}$. Enamel demineralization during orthodontic treatment. Etiology and prevention. Aust Dent J. 1997; 42: 322-327.

9. Artun J, Bbrobakken OB. Prevelance of white spots after orthodontic treatment with multiband appliances. Eur J Orthod 1986;8:229-234.

10. Ten Cate J M and Duijsters P P. Alternating demineralization and remineralization of artificial enamel lesions. Caries Res. 1982; 16: 201-210.

11. Ogaard B. Prevalence of white spot lesions in 19-year-olds: A study on untreated and orthodontically treated persons 5 years after treatment. Am J Orthod Dentofacial Orthop. 1989 96:423-427.

12. Todd MA, Staley RN, Kanellis MJ, Donly KJ, Wefel JS. Effect of a fluoride varnish on demineralization adjacent to orthodontic brackets. Am J Orthod Dentofacial Orthop. 1999;116:159-167.

13. Bishara SE, Vonwald L, Zamtua J, Damon PL. Effects of various methods of chlorhexidine application on shear bond strength. Am J Orthod Dentofacial Orthop. 1998;114:150-153.

14. Silverstone LM. Fissure sealants laboratory studies. Caries Res. 1974;8:2-26.

15. Von Fraunhofer JA, AlJen DJ, Orbell GM. Laser etching of enamel for direct bond. Angle Orthod.1993;63:73-76.

16. Grootveld M, Baysan A, Sidiiqui N, Sim J, Silwood C, Lynch E. History of the clinical applications of ozone. In: Lynch E, editor. Ozone: the revolution in dentistry. London: Quintessence Publishing Co; 2004. pp. 23-30.

17. Baysan A, Lynch E. The use of ozone in dentistry and medicine. Prim Dent Care. 2005; 12:47-52.

18. Celiberti P, Pazera $\mathrm{P}$ and Lussi A. The impact of ozone treatment on enamel physical properties. Am J of Dent. 2006; 19: 67-72. 
19. Baysan A and Lynch E. Treatment of cervical sensitivity with a root sealant. Am J of Dent. 2003; 16: 135-138.

20. Baysan A and Lynch E. Effect of ozone on the oral microbiota and clinical severity of primary root caries. Am J of Dent. 2004; 17: 56-60.

21. Arita M, Nagayoshi M, Fukuizumi T. Microbicidal efficacy of ozonated water against Candida albicans adhering to acrylic denture plates. Oral Micr and Immun. 2005; 20: 206-210.

22. Dahnhardt J E, Jaeggi T and Lussi A. Treating open carious lesions in anxious children with ozone. A prospective controlled clinical study. Am J of Dent. 2006;19: 267-270.

23. Huth K C, Jakob F M, Saugel B, Cappello C, Paschos E, Hollweck R, Hickel Rand Brand K. Effect of ozone on oral cells compared with established antimicrobials. EurJ of Oral Sci. 2006; 114: 435-440.

24. Baysan A and Lynch E. Clinical reversal of root caries using ozone: 6-month results. Am J of Dent 2007; 20: 203-208.

25. Baysan A and Beighton D. Assessment of the ozone-mediated killing of bacteria in infected dentine associated with non-cavitatedocclusal carious lesions. Caries Res. 2007; 41: 337-341.

26. Valacchi, G., Fortino, V. and Bocci, V. The dual action of ozone on the skin. Br J of Derm. 2005; 153: 1096-1100.

27. Pate P V, Kumar, V, Kumar S GD V and Patel, A. Therapeutic effect of topical ozonated oil on the epithelial healing of palatal wound sites: a planimetrical and cytological study. $J$ of Invest and Clinic Dent. 2011; 2: 248-258.

28. Kim H, Noh S, Han Y,and Park Y. Therapeutic Effects of Topical Application of Ozone on Acute Cutaneous Wound Healing. J Korean Med Sci. 2009; 24: 368-374.

29. Pattanaik B, Jetwa D, Pattanaik S, Manglekar S, Naitam DN, Dani A. Ozone therapy in dentistry: A literature review. J Inter discip Dent 2011, 1: 87-92.

30. Sengun A, Sari Z, Ramoglu SI, Malkoç S, Duran I. Evaluation of the dental plaque $\mathrm{pH}$ recovery effect of a xylitol lozenge on patients with fixed orthodontic appliances. Angle Orthod. 2004;74:240-4. 
Egyptian

Orthodontic Journal

31. Derks A, Frencken J, Bronkhorst E, Kuijpers-Jagtman AM, Katsaros C. Effect of chlorhexidine varnish application on mutans streptococci counts in orthodontic patients. Am J Orthod Dentofacial Orthop. 2008;133:435-9.

32. Tufekci E, Casagrande ZA, Lindauer SJ, Fowler CE, Williams KT. Effectiveness of an essential oil mouth rinse in improving oral health in orthodontic patients. Angle Orthod. 2008;78:294-8.

33. Marchisio O, Esposito MR, Genovesi A. Salivary $\mathrm{pH}$ level and bacterial plaque evaluation in orthodontic patients treated with Recaldent products. Int J Dent Hyg. 2010;8:232-6.

34. Cildir SK, Germec D, Sandalli N, et al. Reduction of salivary mutans streptococci in orthodontic patients during daily consumption of yoghurt containing probiotic bacteria. Eur J Orthod. 2009;31:407-11.

35. Bergstrand F and Twetman A. Review on Prevention and Treatment of Post-Orthodontic White Spot Lesions - Evidence-Based Methods and Emerging Technologies. Open Dent J. 2011; 5: 158-162.

36. Hodson N, Dunne SM. Using ozone to treat dental caries. J Esth.Rest Dent. 2007;19:303-305.

37. Al Shamsi AH, Cunningham JL, Lamey PJ, Lynch E. The effects of ozone gas application on shear bond strength of orthodontic brackets to enamel. Am J Dent. 2008;21:35-38.

38. Kronenberg O, Lussi A, Ruf S. Preventive effect of ozone on the development of white spot lesions during multibracket appliance therapy. Angle Orthod. 2009;79:64-69.

39. Baysan A and Lynch E. The use of ozone in dentistry and medicine. Prim Dent Care. 2005; 12:47-52.

40. Baysan A and Lynch E. The use of ozone in dentistry and medicine. Part 2. Ozone and root caries. Prim Dent Care. 2006;13:37-41.

41. Azarpazhooh A and Lime back H. The application of ozone in dentistry: a systematic review of literature. J Dent. 2008;36:104-116.

42. Al- Shamsi A. Assessment of enamel changes during fixed orthodontic treatment with and without ozone. PhD, School of Medicine and Dentistry Queen's University of Belfast. 2007 
43. Shiota G, Shiba A, Tsukasaki H, Kanaisi A, Kurihara N. Effect of newly developed ozone containing gel. IOA $17^{\text {th }}$ World Ozone Congress-Strasbourg 2005.

44. Papa F, Parodi FE, Teti S, Ricci G . Process for making ozonized olive oil gel and the gel obtained. Publication date: 02/05/2009. At http:// www. faqs. Org /patents/ app/ 20090035387.

45. Lussi A and Francescut P. Use of the DIAGNO dent in detecting and monitoring caries lesions and residual caries for ozone treatment. Ozone: The Revolution in Dentistry, by Lynch E, Quintessence publishing Co, Ltd. New Malden, Uk. 2004; Chapter 2.1, 49-59.

46. Hegde MN, Shetty S, Pardal D. Remineralization of enamel sub-surface lesion using casein phosphopeptide amorphous calcium phosphate. A quantitative energy dispersive X-ray analysis. J of Conserv. Dent. 2007; 10:19-25.

47. Avery JK and Bernick S. Oral Development and Histology. The medical publishers, Inc., 2nd edition 1994.

48. Legeros RZ, Sakae T, Bautista C, Retino M, Legero JP. Magnesium and Crbonate in enamel and synthetic apetites. Advanc in Dent Res. 1996; 10225:231.

49. Baysan A, Whiley RA, Lynch E. Antimicrobal effect of novel ozone generating device on micro-organisms associated with primary root carious lesion in vitro. Caries Res. 2000; 34:498-501.

50. Baysan A, Lynch E: The use of ozone in dentistry and medicine. Part 2. Ozone and root caries. Prim Dent Care 2006;13 37-41.

51. Amaechi BT, Higham SM. In vitro remineralization of eroded enamel lesions by saliva. J of Dent.2001; 29: 371-376.

52. Aljehani A, Yousif $M$ A, Angmar-Mansson B and Shi X Q. Longitudinal quantification of incipient carious lesions in postorthodontic patients using a Fluorescence method. Eur J of Oral Ssci.2006;114: 430-434.

53. Cehreli S, Guzey A, Arhun N, Unver B. The Effects of Prophylactic Ozone Pretreatment of Enamel on Shear Bond Strength of Orthodontic Brackets Bonded with Total or Self-Etch Adhesive Systems. Eur J Dent. 2010; 4: 367-373.

54. Al-Khateeb S, Forsberg CM, de Josselin de Jong E, Angmar-Mansson B. A longitudinal laser fluorescence study of white spot lesions in orthodontic patients. Am J Orthod Dentofacial Orthop. 1998;113:595-602. 
Egyptian

Orthodontic Journal

55. Shi XQ, Tranæus S, Angmar-Mannson B. Comparison of QLF and DIAGNOdent for quantification of smooth surface caries. Caries Res. 2001;35:21-26.

56. Benson PE, Pender N, Higham SM. Quantifying enamel demineralization from teeth with orthodontic brackets-a comparison of two methods. Eur J Orthod. 2003;25:149-165.

57. Haikel Y, Frank RM, Voegel JC. Scanning electron microscopy of the human enamel surface layer of incipient carious lesions. Caries Res. 1983;17:1-13

58. Arends J, Jongebloed WL, Schuthof J. Ultrastructure of de- and remineralization. In: Leach SA, Edgar WM, eds. Demineralization and remineralization of teeth. Oxford: IRL Press. 1983;155-63.

59. Gorelick L, Geiger AM, Gwinnett AJ. Incidence of white spot formation after bonding and banding. Am J Orthod. 1982; 81:93-98

60. Alexander SA.The effect of fixed and functional appliances on enamel decalcifications in early class II treatment. Am J Orthod Dentofacial Orthop. 1993;103:45-47.

61. Jenatschke F, Elsenberger E, Welte H D and Schlagenhauf U. Influence of repeated chlorhexidine varnish applications on mutans streptococci counts and caries increment in patients treated with fixed orthodontic appliances. J of Orofacial Orthoped. 2001; 62: 36-45.

62. Attin R, Thon $\mathrm{C}$, Schlagenhauf $\mathrm{U}$ et al. Recolonization of mutanssteptococci on teeth with orthodontic appliances after antimicrobial therapy. Eur J of Orthod. 2005; 27: 489-493.

63. Hessa E, Campbell PM, Honeyman AL, Buschang PH. Determinants of enamel decalcification during simulated orthodontic treatment. Angle Orthod. 2011;81:836-842.

64. Retief DH. Effect of conditioning the enamel surface with phosphoric acid. J Dent Res. 1973;52:333-341.

65. Chow CK, Wu CD and Evans CA. In Vitro Properties of Orthodontic Adhesives with Fluoride or Amorphous Calcium Phosphate. Inter J of Dent. Volume 2011: 1-8. 